\title{
Análises físico-químicas e microbiológicas de água de poços utilizada na produção alimentícia em um complexo turístico do Estado do Ceará
}

Physicochemical and microbiological analyzes of water from wells used in food production in a tourist complex in the State of Ceará

Análisis fisicoquímicos y microbiológicos de agua de pozos utilizados en la producción de alimentos en un complejo turístico del Estado de Ceará

Amauri Barbosa da Silva Junior ORCID: https://orcid.org/0000-0002-1647-2331 Universidade Estadual do Ceará, Brasil E-mail: amauribdsj@gmail.com

Maciella Freire Santos Gama

ORCID: https://orcid.org/0000-0002-7406-183X Universidade Estadual do Ceará, Brasi E-mail: maciella@gmail.com

Luciana Adriano Pereira Figueiredo ORCID: https://orcid.org/0000-0002-7244-7974 Universidade Estadual do Ceará, Brasi E-mail: clarice.araujo@uece.br

Clarice Maria Araújo Chagas Vergara

ORCID: https://orcid.org/0000-0003-1709-9951 Universidade Estadual do Ceará, Brasi E-mail: clarice.araujo@uece.br

\begin{abstract}
Resumo
A água é uma substância essencial para todos os seres vivos, além de ser indispensável para a indústria, comércio e serviços, sobretudo alimentícios. Contudo, sabe-se que o Brasil, mesmo sendo um país privilegiado em relação as reservas hídricas, apresenta uma distribuição desigual das mesmas, como é observado ao se comparar as regiões Norte e Nordeste. Em paralelo a isto, o desenvolvimento de poços se tornou uma importante medida na tentativa de contornar os problemas com a seca em determinadas regiões. O presente trabalho teve como objetivo analisar a qualidade da água de poços utilizada na produção alimentícia de um complexo turístico do estado do Ceará, por meio de parâmetros físicoquímicos e microbiológicos, no período de 2019 a 2021. Foram realizadas 37 analises, onde os parâmetros físicoquímicos verificados foram: pH, Cloretos, Cloro residual, Dureza total, Sólidos totais, Ferro, Nitrato, Nitrito, Sódio e Turbidez. Microbiologicamente analisou-se: coliformes totais e Escherichia coli. Os procedimentos de coleta, acondicionamento e preservação seguiram a metodologia descrita no Stanard Methods for the Examination for Water ans Wastewater. Os resultados obtidos indicaram que parâmetros físico-químicos pH, Nitrato, Nitrito e Turbidez encontraram-se satisfatórios. Os parâmetros de Cloretos, Sólidos totais, Ferro, Sódio, apresentaram algum tipo de inconformidade ao longo das análises em relação aos valores preconizados pela legislação brasileira e da OMS. Já os parâmetros microbiológicos apresentaram-se insatisfatórios em relação aos Coliformes totais em 17,95\% das análises, em relação a $E$. coli houve apenas uma falha, contudo, pode ser explicado devido à baixa concentração de Cloro residual na mesma análise.
\end{abstract}

Palavras-chave: Água subterrânea; Qualidade da água; Potabilidade.

\begin{abstract}
Water is an essential substance for all living beings, as well as essential to industry, commerce and services, especially food. However, it is known that Brazil, despite being a privileged country in relation to water reserves, has an unequal distribution of water reserves, as observed when comparing the North and Northeast regions. At the same time, the development of wells has become an important measure in an attempt to overcome the problems of sequestration in certain regions. This study aimed to analyze the water quality of two wells used in food production of a tourist complex outside the state of Ceará, through physical-chemical and microbiological parameters, in the period from 2019 to 2021. 37 analyzes were carried out, where the physicochemical parameters verified were: $\mathrm{pH}$, Chlorides, Residual Chlorine, Total Hardness, Total Solids, Iron, Nitrate, Nitrite, Sodium and Turbidity. Microbiologically analyzed: total coliforms and Escherichia coli. The collection, conditioning and conservation procedures followed the methodology set forth in the Standard Methods for the Examination of Water and Wastewater. The results obtained indicated that the
\end{abstract}


physicochemical parameters $\mathrm{pH}$, Nitrate, Nitrite and Turbidity were satisfactory. The parameters of Chlorides, Total Solids, Iron, Sodium showed some type of non-conformity throughout the analysis in relation to the values recommended by the Brazilian legislation and the WHO. The unsatisfactory microbiological parameters in relation to Coliforms totalized $17.95 \%$ of the analysis, in relation to E. coli there was only one failure, however, it can be explained by the low concentration of residual chlorine, not the same analog.

Keywords: Groundwater; Water quality; Potability.

\section{Resumen}

El agua es una sustancia esencial para todos los seres vivos, además de indispensable para la industria, el comercio y los servicios, especialmente la alimentación. Sin embargo, se sabe que Brasil, a pesar de ser un país privilegiado en relación a las reservas de agua, tiene una distribución desigual de las reservas de agua, como se observa al comparar las regiones Norte y Nordeste. Paralelamente, el desarrollo de pozos se ha convertido en una medida importante en un intento por superar los problemas de sequía en determinadas regiones. Este estudio tuvo como objetivo analizar la calidad del agua de los pozos utilizados en la producción de alimentos de un complejo turístico en el estado de Ceará, a través de parámetros físico-químicos y microbiológicos, en el período de 2019 a 2021.Se realizaron 37 análisis, donde se Los parámetros fisicoquímicos verificados fueron: pH, Cloruros, Cloro Residual, Dureza Total, Sólidos Totales, Hierro, Nitrato, Nitrito, Sodio y Turbidez. Analizados microbiológicamente: coliformes totales y Escherichia coli. Los procedimientos de recolección, acondicionamiento y conservación siguieron la metodología descrita en los Métodos estándar para el examen de agua y aguas residuales. Los resultados obtenidos indicaron que los parámetros fisicoquímicos pH, Nitrato, Nitrito y Turbidez fueron satisfactorios. Los parámetros de Cloruros, Sólidos Totales, Hierro, Sodio mostraron algún tipo de no conformidad a lo largo de los análisis en relación a los valores recomendados por la legislación brasileña y la OMS. Los parámetros microbiológicos fueron insatisfactorios en relación a Coliformes totales en el $17.95 \%$ de los análisis, en relación a E. coli solo hubo una falla, sin embargo, se puede explicar por la baja concentración de cloro residual en el mismo análisis.

Palabras clave: Agua subterrânea; Calidad del agua; Potabilidad.

\section{Introdução}

Além de ser essencial para todos os seres vivos, a água também é indispensável para o comércio e indústrias no Brasil e no mundo, uma vez que a mesma é utilizada em diversas etapas dos processos produtivos. No entanto, caso não haja um melhor gerenciamento deste recurso, as pessoas podem vir a sofrer com a sua escassez (Tavares e Araújo, 2020).

O Brasil possui significativa reserva hídrica, totalizando $12 \%$ das reservas mundiais, contudo, mesmo privilegiado, existe uma distribuição desigual ao longo de seu território. Tal fato pode ser observado ao se comparar a região Norte, que detém $70 \%$ de toda a reserva hídrica do país, com a região Nordeste, que detém apenas 3\% das reservas brasileiras (Castro, 2012).

A construção de poços subterrâneos é uma alternativa para o acesso à água, principalmente na região Nordeste, devido aos períodos de seca comumente enfrentados. As águas subterrâneas, mesmo sendo mais protegidas de contaminantes antropogênicos em relação às superficiais, apresentam composição química que se altera mais facilmente em relação ao tipo de solo em que estão armazenadas, podendo torná-las de baixa qualidade caso possuam minerais dissolvidos e ou precipitados (Fitts, 2002). Segundo o Sistema de Informações de Águas Subterrâneas (SGB, 2021), o Ceará possui 31.720 poços cadastrados em todo o estado.

Segundo a Portaria n. ${ }^{\circ} 888 / 2021$, água potável é aquela que atende aos padrões de potabilidade estabelecidos por lei, que não impliquem em riscos à saúde. Logo, para que a água seja considerada potável, deverá estar dentro dos padrões segundo os parâmetros físico-químicos, microbiológicos e organolépticos (Brasil, 2021).

Nas Unidades de Alimentação e Nutrição (UAN), os alimentos estão suscetíveis a diferentes fontes de contaminação durante o seu processamento, sendo uma dessas fontes a água (Coelho et al., 2010). Como consequência desta possível contaminação, surgem as doenças de veiculação hídrica, onde o consumo causa doenças diarreicas infecciosas, devido a presença de patógenos na água (Gruber, Ercumen e Colford, 2014). Para que tal risco seja reduzido, segundo a Resolução n. ${ }^{\circ} 216$ de 2004, apenas água potável deve ser utilizada para manipulação de alimentos (Brasil, 2004).

Diante dos fatos supracitados, o presente trabalho tem como objetivo analisar os aspectos físico-químicos e microbiológicos da água de poços utilizada na produção alimentícia em um complexo turístico do estado do Ceará. 


\section{Metodologia}

Trata-se de um estudo transversal do tipo quantitativo, em que se utilizaram dados para atestar a potabilidade da água, através de parâmetros físico-químicos como pH, Cloretos, Cloro residual, Dureza total, Sólidos totais dissolvidos, Ferro, Nitrato, Nitrito, Sódio e Turbidez e microbiológicos como Coliformes totais e Escherichia coli provenientes de análises previamente realizadas. As amostras foram coletadas em locais de preparo de alimentos em cinco áreas diferentes, nomeadas de áreas "A" até "E", de um complexo turístico localizado no estado do Ceará, as coletas das amostras foram realizadas em dias com ausência de chuva de no mínimo 24 horas, durante os anos de 2019 a 2021. As coletas foram realizadas por um responsável técnico e encaminhadas a um laboratório especializado para posterior análise.

Os ensaios foram realizados adotando a metodologia descrita no Standard Methods for the Examination for Water ans Wastewater (APHA, 2017), que podem ser utilizados para águas residuais e bacias hidrográficas, contudo, os métodos analíticos são categorizados com base no constituinte e não no tipo de água.

Os resultados foram tabulados no software Excel® versão 2019, onde foram agrupados conforme o ano de sua realização. Em seguida foram calculados média e desvio padrão das análises para fins de comparação com as legislações vigentes.

\section{Resultados e Discussão}

De acordo com os resultados, observou-se que a maioria dos parâmetros analisados se encontram em conformidade com a Portaria de n. ${ }^{\circ} 888$ de 4 de maio de 2021 do Ministério da Saúde, apresentando apenas alguns valores acima do permitido.

Para os valores de pH, observaram-se que os resultados variaram de 6,36 a 6,88 (Tabela 1), 6,54 a 7,48 (Tabela 2) e 6,63 a 7,38 (Tabela 3), nota-se que os valores de $\mathrm{pH}$ da Tabela 2 apresentaram uma maior diferença de $\mathrm{pH}$ ao longo do ano, contudo, todos estão dentro da faixa de 6,0 - 9,0 estabelecida pela portaria do MS.

Tabela 1 - Resultados dos parâmetros físico-químicos analisados no ano de 2019. Aquiraz, 2021.

\begin{tabular}{|c|c|c|c|c|c|c|c|}
\hline Parâmetro & Área A & Área B & Área C & Área D & Área E & $\mathbf{V M P} \mathbf{P}^{(1)}$ & $\mathbf{V M P} \mathbf{P}^{(2)}$ \\
\hline Físico-Químicos & $\mathrm{X} \pm \mathrm{DP}$ & $\mathrm{X} \pm \mathrm{DP}$ & $\mathrm{X} \pm \mathrm{DP}$ & $\mathrm{X} \pm \mathrm{DP}$ & $\mathrm{X} \pm \mathrm{DP}$ & & \\
\hline $\mathrm{pH}$ & $6,83 \pm 0,31$ & $6,88 \pm 0,17$ & $6,36 \pm 0,24$ & $6,81 \pm 0,61$ & $6,63 \pm 0,23$ & $6,0-9,0^{(1)}$ & $6,5-8,5^{(2)}$ \\
\hline Cloretos & $211,6 \pm 229,97$ & $\begin{array}{c}298,64 \pm \\
190,04\end{array}$ & $23,96 \pm 3,31$ & $52,11 \pm 1,69$ & $39,13 \pm 3,53$ & $250,00^{(1)}$ & $250,00^{(2)}$ \\
\hline Cloro Residual & $1,08 \pm 0,61$ & $0,80 \pm 0,21$ & $0,26 \pm 0,14$ & $0,94 \pm 0,06$ & $0,52 \pm 0,02$ & $5,00^{(1)}$ & $5,00^{(2)}$ \\
\hline Dureza Total & $246,67 \pm 53,79$ & $\begin{array}{c}171,66 \pm \\
159,76\end{array}$ & $19,23 \pm 9,59$ & $92,86 \pm 13,36$ & $56,27 \pm 6,57$ & $300,00^{(1)}$ & $100,00^{(2)}$ \\
\hline Sólidos Totais & $\begin{array}{c}699,86 \pm \\
370,93\end{array}$ & $\begin{array}{c}798,53 \pm \\
435,23\end{array}$ & $56,42 \pm 26,10$ & $\begin{array}{c}234,17 \pm \\
17,57\end{array}$ & $\begin{array}{c}178,64 \pm \\
12,04\end{array}$ & $500,00^{(1)}$ & $500,00^{(2)}$ \\
\hline Ferro & $0,41 \pm 0,13$ & $0,19 \pm 0,06$ & $0,06 \pm 0,04$ & $0,11 \pm 0,01$ & $0,07 \pm 0,04$ & $0,3^{(1)}$ & $0,3^{(2)}$ \\
\hline Nitrato & $1,48 \pm 0,32$ & $0,89 \pm 0,11$ & $1,62 \pm 0,46$ & $4,04 \pm 1,54$ & $3,84 \pm 0,06$ & $10,00^{(1)}$ & $10,00^{(2)}$ \\
\hline Nitrito & $0,05 \pm 0$ & $0,04 \pm 0,02$ & $0,03 \pm 0,01$ & $0,04 \pm 0,02$ & $0,04 \pm 0,02$ & $1,00^{(1)}$ & - \\
\hline Sódio & $99,67 \pm 50,22$ & $107,5 \pm 70,5$ & $19,8 \pm 12,96$ & $41 \pm 18$ & $37,50 \pm 19,50$ & $200,00^{(1)}$ & $200,00^{(2)}$ \\
\hline Turbidez & $1,33 \pm 0,97$ & $1,05 \pm 0,95$ & $0,94 \pm 0,85$ & $1,05 \pm 0,95$ & $1,05 \pm 0,95$ & $5,0^{(1)}$ & $5,0^{(2)}$ \\
\hline
\end{tabular}

Nota: ${ }^{(1)}$ Portaria n. 888 de 4 de maio de 2021 - Ministério da Saúde; (2) WHO -Guidelines for drinking-water quality (2008); VMP = Valores Máximos Permitidos; X = Média; DP = Desvio padrão. Fonte: Autor (2021). 
Tabela 2 - Resultados dos parâmetros físico-químicos analisados no ano de 2020. Aquiraz, 2021.

\begin{tabular}{|c|c|c|c|c|c|c|c|}
\hline Parâmetro & Área A & Área B & Área C & Área D & Área E & $\mathbf{V M P} \mathbf{P}^{(\mathbf{1})}$ & $\mathbf{V M P}^{(2)}$ \\
\hline $\begin{array}{l}\text { Físico- } \\
\text { Químicos }\end{array}$ & $\mathrm{X} \pm \mathrm{DP}$ & $\mathrm{X} \pm \mathrm{DP}$ & $\mathrm{X} \pm \mathrm{DP}$ & $\mathbf{X} \pm \mathbf{D P}$ & $\mathrm{X} \pm \mathrm{DP}$ & & \\
\hline $\mathrm{pH}$ & $6,83 \pm 0,35$ & $7,48 \pm 0,08$ & $6,72 \pm 0,24$ & $6,54 \pm 0,04$ & $6,90 \pm 0,56$ & $6,0-9,0^{(1)}$ & $6,5-8,5^{(2)}$ \\
\hline Cloretos & $\begin{array}{c}310,89 \\
\pm 241,10\end{array}$ & $77,13 \pm 43,33$ & $29,37 \pm 4,38$ & $62,80 \pm 8,05$ & $40,72 \pm 4,06$ & $250,00^{(1)}$ & $250,00^{(2)}$ \\
\hline Cloro Residual & $0,41 \pm 0,37$ & $1,04 \pm 0,64$ & $0,79 \pm 0,47$ & $0,62 \pm 0,12$ & $0,68 \pm 0,18$ & $5,00^{(1)}$ & $5,00^{(2)}$ \\
\hline Dureza Total & $\begin{array}{c}213,12 \pm \\
46,70\end{array}$ & $163 \pm 21,73$ & $30,14 \pm 9,02$ & $102,9 \pm 2,9$ & $65,5 \pm 8,5$ & $300,00^{(1)}$ & $100,00^{(2)}$ \\
\hline Sólidos Totais & $\begin{array}{c}642,45 \pm \\
309,24\end{array}$ & $223,34 \pm 6,39$ & $86,5 \pm 14,8$ & $\begin{array}{c}225,04 \pm \\
22,15\end{array}$ & $\begin{array}{c}148,92 \pm \\
9,92\end{array}$ & $500,00^{(1)}$ & $500,00^{(2)}$ \\
\hline Ferro & $0,38 \pm 0,19$ & $0,28 \pm 0,03$ & $0,14 \pm 0,04$ & $0,13 \pm 0,03$ & $0,12 \pm 0,02$ & $0,3^{(1)}$ & $0,3^{(2)}$ \\
\hline Nitrato & $2,28 \pm 2$ & $0,42 \pm 0,42$ & $2,79 \pm 1,08$ & $7,12 \pm 2,48$ & $5,18 \pm 1,62$ & $10,00^{(1)}$ & $10,00^{(2)}$ \\
\hline Nitrito & $0,03 \pm 0,02$ & $0,32 \pm 0,36$ & $0,05 \pm 0,02$ & $0,51 \pm 0,46$ & $0,08 \pm 0,03$ & $1,00^{(1)}$ & - \\
\hline Sódio & $\begin{array}{c}145,82 \pm \\
96,14\end{array}$ & $24,83 \pm 8,78$ & $35,37 \pm 25,88$ & $35,45 \pm 0,75$ & $35 \pm 8$ & $200,00^{(1)}$ & $200,00^{(2)}$ \\
\hline Turbidez & $2,37 \pm 1,71$ & $0,29 \pm 0,3$ & $0,16 \pm 0,06$ & $0,06 \pm 0,05$ & $0,79 \pm 0,69$ & $5,0^{(1)}$ & $5,0^{(2)}$ \\
\hline
\end{tabular}

Nota: (1) Portaria n. ${ }^{\circ} 888$ de 4 de maio de 2021 - Ministério da Saúde; ${ }^{(2)}$ WHO -Guidelines for drinking-water quality (2008); VMP = Valores Máximos Permitidos; X = Média; DP = Desvio padrão. Fonte: Autor (2021).

Tabela 3 - Resultados dos parâmetros físico-químicos analisados no ano de 2021. Aquiraz, 2021.

\begin{tabular}{l|c|l|c|c|c|c}
\hline $\begin{array}{l}\text { Parâmetro } \\
\text { Físico- } \\
\text { Químicos }\end{array}$ & Área A & Área B & Área C & Área E & VMP(1) & VMP(2) \\
\cline { 2 - 7 } & $\mathbf{X} \pm \mathbf{P}$ & $\mathbf{X} \pm \mathbf{D P}$ & $\mathbf{X} \pm \mathbf{D P}$ & & \\
\hline $\mathrm{pH}$ & $6,63 \pm 0$ & $7,38 \pm 0$ & $6,85 \pm 0,14$ & $6,64 \pm 0$ & $6,0-9,0^{(1)}$ & $6,5-8,5^{(2)}$ \\
\hline Cloretos & $734,16 \pm 0$ & $46,18 \pm 0$ & $21,39 \pm 0,49$ & $35,49 \pm 0$ & $250,00^{(1)}$ & $250,00^{(2)}$ \\
\hline Cloro Residual & $0,64 \pm 0$ & $0,95 \pm 0$ & $0,19 \pm 0,03$ & $0,55 \pm 0$ & $5,00^{(1)}$ & $5,00^{(2)}$ \\
\hline Dureza Total & $382 \pm 0$ & $133 \pm 0$ & $21 \pm 3$ & $52 \pm 0$ & $300,00^{(1)}$ & $100,00^{(2)}$ \\
\hline Sólidos Totais & $1762,5 \pm 0$ & $208,45 \pm 0$ & $68,78 \pm 0,46$ & $149,38 \pm 0$ & $500,00^{(1)}$ & $500,00^{(2)}$ \\
\hline Ferro & $0,1 \pm 0$ & $0,1 \pm 0$ & $0,10 \pm 0$ & $0,1 \pm 0$ & $0,3^{(1)}$ & $0,3^{(2)}$ \\
\hline Nitrato & $2,58 \pm 0$ & $0,1 \pm 0$ & $1,92 \pm 0,06$ & $6,9 \pm 0$ & $10,00^{(1)}$ & $10,00^{(2)}$ \\
\hline Nitrito & $0,01 \pm 0$ & $0,01 \pm 0$ & $0,01 \pm 0$ & $0,01 \pm 0$ & $1,00^{(1)}$ & - \\
\hline Sódio & $349,6 \pm 0$ & $18,1 \pm 0$ & $15,34 \pm 0,09$ & $27,96 \pm 0$ & $200,00^{(1)}$ & $200,00^{(2)}$ \\
\hline Turbidez & $0,34 \pm 0$ & $0,46 \pm 0$ & $0,40 \pm 0,06$ & $0,11 \pm 0$ & $5,0^{(1)}$ & $5,0^{(2)}$ \\
\hline
\end{tabular}

Nota: ${ }^{(1)}$ Portaria n. ${ }^{\circ} 888$ de 4 de maio de 2021 - Ministério da Saúde; ${ }^{(2)}$ WHO -Guidelines for drinking-water quality (2008); VMP = Valores Máximos Permitidos; X = Média; DP = Desvio padrão. Fonte: Autor (2021). 
No trabalho desenvolvido por Osiemo, Ogendi e M’Erimba (2019), foi realizada uma análise da água em poços profundos e artesianos da cidade de Marigat, localizada no Quênia, onde os valores de $\mathrm{pH}$ variaram de 6,42 a 7,38. Oliveira e colaboradores (2018) analisando a composição físico-química de bebedouros de escolas em Timon, estado do Maranhão, encontraram valores de pH variando entre 6,85 e 7,28. Souza, Frade e Soares (2018), observaram valores médios mais elevados em poços, no município de Iguatama - MG, porém, encontravam-se dentro dos padrões de $\mathrm{pH}$ requeridos. Os resultados obtidos são superiores aos encontrados por Coelho et al. (2017), cujos valores encontrados chegavam a 8,39.

Os cloretos podem estar presentes naturalmente em águas subterrâneas, pois, devido a água ser um solvente universal acaba por agregar muitas substâncias dissolvidas. A portaria do MS estabelece o teor de cloretos em $250 \mathrm{mg} / \mathrm{L}$ como valor máximo permitido para água potável. Conforme os resultados as áreas A e B foram as únicas que apresentaram médias acima do que é permitido pela legislação, sendo 310,89 e 734,16 mg/L na área A nos anos de 2020 e 2021 e 298,64 mg/L em 2019 na área B, contudo, este parâmetro foi normalizado com o passar dos anos nesta área e atualmente encontra-se satisfatório. Silva, Barbosa e Silva (2018) em estudo realizado na cidade de Macapá, observaram níveis de cloretos muito inferiores aos do presente estudo, variando entre 12,00 a $23,14 \mathrm{mg} / \mathrm{L}$.

O cloro é a substância mais utilizada para a desinfecção, sendo responsável pela eliminação de alguns microrganismos patogênicos presentes na água, devido a isto, é necessário que seja feito um controle da sua concentração para evitar problemas a saúde pública (Soares et al., 2016). Ambas as portarias, n. ${ }^{\circ}$ 888/2021 e da OMS, estabelecem 5,00 mg/L como valor máximo de concentração de cloro residual que deve estar presente na água. Em relação a este parâmetro, foi observado que ao longo dos últimos anos os resultados obtidos variaram entre 0,19 a 1,04 mg/L, estando satisfatório e dentro do que é preconizado pelas legislações nacional e internacional. No estudo realizado por Coelho e colaboradores (2017), as amostras apresentaram ausência de cloro residual, o que segundo o autor possibilita a presença e multiplicação de patógenos na água, pois o teor de cloro em quantidades adequadas após a cloração é o que irá eliminar os patógenos e garantir qualidade da água.

O parâmetro de dureza total da água está relacionada a formação de precipitados na solução. De maneira satisfatória, apenas a área A no ano de 2021 excedeu o limite permitido pela legislação nacional, ademais as águas de todas as áreas, nos três períodos analisados, apresentam-se dentro do limite permitido pela Portaria n. ${ }^{\circ}$ 888/2021 do MS conforme apresentado nas Tabelas 1, 2 e 3, contudo, quando comparada as recomendações da Organização Mundial da Saúde (2008) apenas as áreas C e E apresentaram resultados dentro do limite permitido, esta legislação acaba sendo mais rigorosa que a nacional, devido ao valor de $100 \mathrm{mg} / \mathrm{L}$ ser limitante para as alterações organolépticas em relações aos íons cálcio e a partir deste valor causar incrustações em tubulações . Crispim et al. (2017), encontrou valores de dureza total variando entre $271 \mathrm{mg} / \mathrm{L} \mathrm{a} 423 \mathrm{mg} / \mathrm{L}$ em 3 poços no município de Pombal-PB, valores semelhantes aos encontrados na área A. Já no trabalho realizado por Ocheli, Otuya e Umayah (2020) os valores de dureza total se encontram entre $46 \mathrm{mg} / \mathrm{L}$ a $96 \mathrm{mg} / \mathrm{L}$ para água de poços artesianos sendo semelhante aos achados nas áreas $\mathrm{C}$ e $\mathrm{E}$.

Os sólidos totais dissolvidos presentes na água não devem ser superiores a $500,00 \mathrm{mg} / \mathrm{L}$, pois, caso haja uma grande concentração de sólidos totais pode causar alterações em relação ao sabor da água. Apenas as áreas A e B não estavam dentro dos padrões de normalidade exigidos pelas legislações nacional Portaria n. . 888/2021 e da OMS (2008), devido a ambas apresentarem valores máximos semelhantes. Ocheli, Otuya e Umayah (2020), tiveram achados muito diferentes em poços artesianos $(0,2$ a $4,1 \mathrm{mg} / \mathrm{L})$ e poços profundos $(0,3$ a $4,4 \mathrm{mg} / \mathrm{L})$ em quatro comunidades da Nigéria, onde a exploração e aproveitamento de petróleo e desenvolvimento de atividades agrícolas estão em alta.

Sabe-se que a ingestão de ferro em quantidades seguras apresenta benefícios a saúde, contudo, a sua ingestão elevada, pode ser tóxica, afetando todos os órgãos, podendo aumentar o risco para doenças cardíacas (Baumgarten; Paiva; Rodrigues, 2014). Para o ferro foram obtidos valores até os limites permitidos por lei, com exceção da área A que por duas vezes, ultrapassou o máximo permitido de $0,3 \mathrm{mg} / \mathrm{L}$. Já Ferreira e colaboradores (2021), ao analisar poços e águas subterrâneas em zonas rurais da região do Humaitá-AM em estações diferentes, obteve valores de no máximo 0,29 mg/L. 
Os valores de nitrato e nitrito obtidos foram inferiores ao estabelecido pela Portaria n. ${ }^{\circ} 888$ de 2021 , do Ministério da Saúde. Contudo, os achados em relação ao nitrato nas áreas D e E foram os mais elevados dentre as cinco áreas. Ocheli, Otuya e Umayah (2020), tiveram achados semelhantes de nitrato em águas de poço (3,7 a 9,6 mg/L) na região ocidental do Delta do Níger. Os nitratos são compostos nocivos para os seres humanos, em altas concentrações, podem causar uma doença denominada metalohemoglobina infantil, sendo esta fatal para crianças (Ana, 2017).

As quantificações dos valores médios de sódio podem ser consultadas nas Tabelas 1, 2 e 3, para as amostras das áreas A à E. Nestas, é possível observar que apenas a área A (Tabela 3) apresentou-se insatisfatória, estando 1,5 vezes acima do padrão permitido, já as demais amostras, encontram-se dentro dos valores máximos deste parâmetro. De acordo com a CETESB (2009), o sódio esta comumente presente em todas as águas naturais, contudo, teores elevados de sódio podem ser consequência de ações antropogênicas ou intrusão de águas marinhas em zonas litorâneas. No estudo realizado por Bezerra e colaboradores (2018), foram observados valores de sódio muito inferiores, ao do presente trabalho, mesmo tendo sido coletados no mesmo município.

$\mathrm{Na}$ análise de turbidez, observou-se valores médios de 0,06 a 2,37 uT. De acordo com a legislação vigente recomendase não exceder 5,0 uT, diante disto, todos os valores encontraram-se satisfatórios. É necessário avaliar o parâmetro da turbidez, pois as partículas em suspensão podem se fixar nos microrganismos patogênicos e oferecer proteção contra o processo de cloração, além de deixarem a água com um aspecto turvo (Mastropaulo; Razzolini, 2018).

A Tabela 4 expressa a quantidade de amostras realizadas, bem como o número de amostras satisfatório e insatisfatório ao padrão de qualidade relativa a presença de coliformes totais e fecais, de acordo com o ano de realização.

Tabela 4 - Coletas e análises microbiológicas conforme o ano de realização. Aquiraz, 2021.

\begin{tabular}{|c|c|c|c|c|c|c|c|c|c|}
\hline & \multicolumn{3}{|c|}{ Ano 2019} & \multicolumn{3}{|c|}{ Ano 2020} & \multicolumn{3}{|c|}{ Ano 2021} \\
\hline Análise & T.A.* & D.P.** & F.P.*** & T.A* & D.P** & F.P.*** & T.A.* & D.P.** & F.P.*** \\
\hline $\begin{array}{c}\text { Coliformes } \\
\text { Totais }\end{array}$ & \multirow[t]{2}{*}{16} & 12 & 4 & \multirow{2}{*}{18} & 15 & 3 & \multirow{2}{*}{5} & 5 & 0 \\
\hline $\begin{array}{c}\text { Escherichia } \\
\text { coli }\end{array}$ & & 15 & 1 & & 18 & 0 & & 5 & 0 \\
\hline
\end{tabular}

Nota: T.A.* = Total de amostras coletadas; D.P.** = Amostras dentro do padrão de qualidade; F.P.*** = Amostras fora do padrão de qualidade. Fonte: Autor (2021).

Pôde-se observar a presença de coliformes totais em 17,95\% de todas as amostras pesquisadas. Já no estudo realizado por Oliveira et al. (2018), o número de poços que apresentaram coliformes totais foram de 70\%, valor bem acima do encontrado no presente estudo. Em estudo realizado por Soares et al. (2018), mostram a presença destes microrganismos em 34,88\% das mais de 10.000 amostras coletadas.

A E. coli, é um indicador de contaminação fecal da água, pois é um microrganismo encontrado na microbiota intestinal de animais (Cartoxa et al.,2020), quanto a sua presença, dentre todas as análises realizadas foi constatada inadequação neste parâmetro uma única vez, tendo sido posteriormente corrigida e em todas as análises subsequentes estavam dentro dos parâmetros indicados, contudo, vale salientar que, o resultado insatisfatório pode ter sido causado pela baixa concentração de cloro na água analisada, o que como visto por Coelho e colaboradores (2017), a ausência ou concentrações baixas acabam por não eliminar todas as bactérias, permitindo que haja a multiplicação das mesmas.

As contaminações por bactérias de natureza entérica, são consideradas grandes problemas de saúde pública, por desencadearem surtos de doenças, como a diarreia, sendo responsável por um alto coeficiente de morbidade e mortalidade, principalmente na população mais jovem (Murray, 2014). 
A Portaria n. ${ }^{\circ} 888$ de 2021, determina que para a água ser considerada potável, sob a ótica dos padrões microbiológicos, deve estar livre de coliformes totais e fecais em cada $100 \mathrm{~mL}$ de água destinada ao consumo humano. Fica determinado que, ao serem detectados amostras positivas, ações corretivas devem ser tomadas com sucessiva repetição dos testes até apresentarem resultados satisfatórios (Brasil, 2021).

\section{Conclusão}

A partir dos resultados obtidos, é possível afirmar que os parâmetros físico-químicos pH, nitratos, nitrito e turbidez encontraram-se dentro da conformidade em todas as análises. É importante salientar que a área $\mathrm{A}$ foi a que obteve mais inadequações em relações aos parâmetros microbiológicos, mantendo-se também insatisfatória em relação a parâmetros físicoquímicos como cloretos, dureza total, sólidos totais e sódio, devendo ser investigadas mais a fundo as causas destas falhas.

Diante do exposto, devido a água ser utilizada diretamente na produção alimentícia do complexo turístico, em quantidades diárias bastante volumosas, devem ser realizadas medidas para a melhoria da qualidade da mesma. Este estudo, é de grande relevância, visto a escassez de estudos sobre a potabilidade das águas subterrâneas de poços utilizadas em produções alimentícias.

\section{Referências}

Ana, A. N. A. (2017). Indicadores de qualidade - Índice de Qualidade das Águas. http://portalpnqa.ana.gov.br/indicadores-indice-aguas.aspx

Apha- American Public Health Association (2017). Standard Methods for the Examinations of Water and Wastewater. American Public Associations. 23th Washington DC.

Baumgarten, M. G. Z., de Paiva, M. L., \& Rodrigues, H. R. S. (2014). Kit Analítico Simplificado: uma ferramenta para avaliação massiva da qualidade da água subterrânea. Águas Subterrâneas, 28(2).

Bezerra, A. D. A., da Rocha, J. C, Nogueira, E. R., de Sousa, D. M. L., Araujo, F. G. D. M., Brandao, M. G. A., \& Pantoja, L. D. M. (2018). Análise situacional da qualidade de água subterrânea oriunda de poços da região metropolitana de fortaleza, ceará, brasil. Acta Biomedica Brasiliensia, 9(1), 94-104.

Brasil. (2004). Ministério da Saúde. Agência Nacional de Vigilância Sanitária (ANVISA). Resolução da Diretoria Colegiada (RDC) n 216 , de 15 de setembro de 2004. Estabelece procedimentos de Boas Práticas para serviço de alimentação, garantindo as condições higiênico-sanitárias do alimento preparado. Diário Oficial da União. https://bvsms.saude.gov.br/bvs/saudelegis/anvisa/2004/res0216_15_09_2004.html

Brasil (2021). Portaria $n^{\circ} .888$, de 4 de maio de 2021. Dispõe sobre os procedimentos de controle e vigilância da qualidade da água para o consumo humano e seu padrão de potabilidade. https://www.in.gov.br/en/web/dou/-/portaria-gm/ms-n-888-de-4-de-maio-de-2021-318461562

Brasil (2021). Serviço Geológico do Brasil (SGB) - Sistema de Informações de Águas Subterrâneas (SIAGAS). http://siagasweb.cprm.gov.br/layout/pesquisa_complexa.php

Cartaxo, R. A., Monteiro, M. D. F. G., Sousa Júnior, D. L. A., Aquino, P. E. A., Sousa Ferreira, S., Marinho, A. L., de Carvalho, M. A. J., Cavalcante, T. M. B.; Saraiva, C. R. N., Silva Leandro, M. K. N., Gracia Leandro, L. M., \& da Silva, R. O. M. (2020). Análise microbiológica da água de um poço profundo no distrito de São Miguel, Mauriti, Ceará. Journal of Medicine and Health Promotion, 5(4), 10-18.

Castro, C. N. (2012). Gestão das águas: experiências internacional e brasileira (No. 1744). Texto para Discussão.

Cetesb, Companhia Ambiental do Estado de São Paulo (2009). Qualidade das águas interiores no Estado de São Paulo. Série de relatórios - Apêndice A: Significado ambiental e sanitário das variáveis de qualidade das águas e dos sedimentos e metodologias analíticas e de amostragem. São Paulo; CETESB.

Coelho, S. C., Duarte, A. N., Amaral, L. S., dos Santos, P. M., Salles, M. J., dos Santos, J. A. A., \& Sotero Martins, A. (2017). Monitoramento da água de poços como estratégia de avaliação sanitária em Comunidade Rural na Cidade de São Luís, MA, Brasil. Revista Ambiente \& Água, 12 (1), 156 - 167.

Coelho, M. I. A, Milagres, M.R.C.R., Martins, L.F.J., Azevedo, C.M.R., \& Santana, C.M.A. (2010). Contaminação microbiológica de ambientes e de superfícies em restaurantes comerciais. Ciência \& Saúde Coletiva, 15, 1597-1606.

Crispim, D. L., Coelho, L., de Oliveira, A. M. B. M., de Andrade, S. O., \& Chaves, A. (2017). Análise físico-química das águas de três poços amazonas no centro da cidade de Pombal-PB. Geografia Ensino \& Pesquisa, 21(2), 155-163.

Ferreira, L. A., Pimentel, E. T., da Silva, R. B. P., \& de Almeida, A. S. (2021). Avaliação da qualidade de potabilidade da água subterrânea em áreas rurais no município de Humaitá/AM. Revista Ibero-Americana de Ciências Ambientais, 12(1), 721-729.

Fitts, C. R. (2002). Groundwater Science. Elsevier.

Grube, J.S., Ercumen, A., \& Colford Jr, J.M. (2014). Coliform bacteria as indicators of diarrheal risk in household drinking water: systematic review and metaanalysis. PLoS One, 9(9), e107429. 
Research, Society and Development, v. 10, n. 10, e271101018839, 2021

(CC BY 4.0) | ISSN 2525-3409 | DOI: http://dx.doi.org/10.33448/rsd-v10i10.18839

Mastropaulo, A. D. A., \& Razzolini, M. T. P. (2018). Qualidade da água de sistema alternativo coletivo de abastecimento para consumo humano: ocorrência de cistos de Giardiae oocistos de Cryptosporidiumem poços de São Paulo, SP. Revista Brasileira de Ciências da Saúde, 22(3), 237-246.

Murray, P. R., Rosenthak, K. S., \& Pfaller, M. A. (2014). Microbiologia Médica. 7 ed. Rio de Janeiro: Elsevier.

Ocheli, A., Otuya, O. B., \& Umayah, S. O. (2020). Appraising the risk level of physicochemical and bacteriological twin contaminants of water resources in part of the western Niger Delta region. Environmental monitoring and assessment, 192(5), 1-16.

Oliveira, E. M., Ribeiro, D. M., Cronemberger, M. G. O., Carvalho, W. F., Lima, M. D. P., \& Sousa, K. R. F. (2018). Análises físico-químicas e microbiológicas da água de bebedouros em escolas públicas da cidade de Timon-MA. PUBVET, 12, 172.

Oliveira, M. M.; Lima, A. S., Mouchrek, A. M., Marques, P. R. B. O., \& Marques, C. V. V. C. O. (2018). Analise físico-quimica e microbiológica de águas de poços artesianos de uso independente. Revista Gestão \& Sustentabilidade Ambiental, 7(3), 624-639.

Osiemo, M. M., Ogendi, G. M., \& M'Erimba, C. (2019). Microbial quality of drinking water and prevalence of water-related diseases in Marigat Urban Centre, Kenya. Environmental health insights, v. 13, p. 1178630219836988.

Silva, L. P., Barbosa, J. P., \& Silva, G. A. (2018). Análise exploratória de dados da qualidade da água de poços amazonas na cidade de Macapá, Amapá, Brasil. Águas Subterrâneas, 32(1), p. 43-51.

Soares, S. S., Arruda, P. N., Lobón, G. S., \& Scalize, P. S. (2016). Avaliação de métodos para determinação de cloro residual livre em águas de abastecimento público. Semina: Ciências Exatas e Tecnológicas, v. 37(1), 119-130.

Soares, T. C., Morais, A. B., Soares, T. C., Oliveira, V. A., Medeiros, S. R. A., \& Carneiro, T. B. (2018). Perfil da água para o consumo humano e notificação de doenças em uma macrorregião do Piauí, Brasil. Revista Brasileira de Higiene e Sanidade Animal, 12(2), 205-215.

Souza, O. T., Frade, P. R., \& Soares, C. A. (2018). Qualidade da água de poços tubulares em Iguatama, Minas Gerais. Revista Verde de Agroecologia e Desenvolvimento Sustentável, 13(5), 637-643.

Tavares, J. M., \& Araújo, W. J. S. Consumo e Escassez de Água Potável em Salvador-Bahia. (2020). Brazilian Journal of Development, 6(9), 70909-70925.

World Health Organization. (2008). Guidelines for drinking-water quality: second addendum. Vol. 1, Recommendations. 